Document downloaded from:

http://hdl.handle.net/10251/102163

This paper must be cited as:

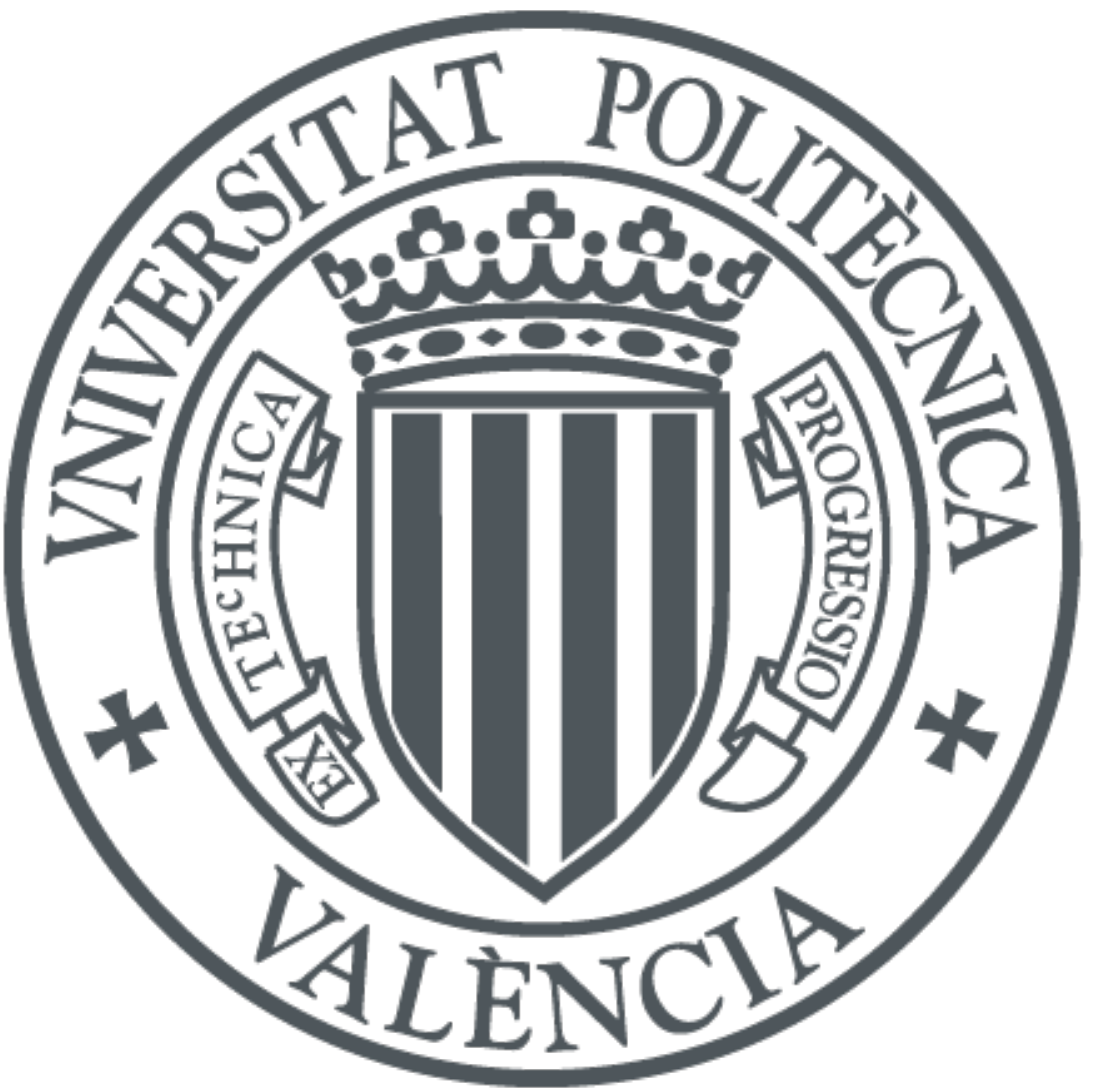

The final publication is available at

https://doi.org/10.1002/cnm.2904

Copyright John Wiley \& Sons

Additional Information 


\title{
Modeling Liver Electrical Conductivity during Hypertonic Injection
}

\author{
Quim Castellví ${ }^{*}$, Patricia Sánchez-Velázquez ${ }^{2}$, Xavier Moll $^{3}$, Enrique Berjano ${ }^{4}$, Anna \\ Andaluz $^{3}$, Fernando Burdío ${ }^{2}$, Bart Bijnens ${ }^{1,5}$ and Antoni Ivorra ${ }^{1,6}$ \\ ${ }^{1}$ Department of Information and Communication Technologies, Universitat Pompeu Fabra, Barcelona, Spain \\ ${ }^{2}$ General Surgery Department, Hospital del Mar, Barcelona, Spain \\ ${ }^{3}$ Departament de Medicina i Cirurgia Animals, Universitat Autònoma de Barcelona, Barcelona, Spain \\ ${ }^{4}$ BioMIT, Department of Electronic Engineering, Universitat Politècnica de València, Spain \\ ${ }^{5}$ ICREA, Barcelona, Spain \\ ${ }^{6}$ Serra Húnter Fellow, Universitat Pompeu Fabra, Barcelona, Spain
}

\begin{abstract}
Metastases in the liver frequently grow as scattered tumor nodules which neither can be removed by surgical resection nor focally ablated. Previously, we have proposed a novel technique based on irreversible electroporation which may be able to simultaneously treat all nodules in the liver while sparing healthy tissue. The proposed technique requires increasing the electrical conductivity of healthy liver by injecting a hypersaline solution through the portal vein. Aiming to assess the capability of increasing the global conductivity of the liver by means of hypersaline fluids, here it is presented a mathematical model which estimates the $\mathrm{NaCl}$ distribution within the liver and the resulting conductivity change. The model fuses wellestablished compartmental pharmacokinetic models of the organ with saline injection models employed for resuscitation treatments and it considers changes in sinusoidal blood viscosity due to the hypertonicity of the solution. Here it is also described a pilot experimental study in pigs in which different volumes of $\mathrm{NaCl} 20 \%$ (from 100 to $200 \mathrm{ml}$ ) were injected through the portal vein at different flow rates (from 53 to $171 \mathrm{ml} / \mathrm{min}$ ). The in vivo conductivity results fit those obtained by the model, both quantitatively and qualitatively, being able to predict the maximum conductivity with a $14.6 \%$ average relative error. The maximum conductivity value was $0.44 \mathrm{~S} / \mathrm{m}$ which corresponds to increasing four times the mean basal conductivity $(0.11 \mathrm{~S} / \mathrm{m})$. The results suggest that the presented model is well suited for predicting on liver conductivity changes during hypertonic saline injection.
\end{abstract}

KEY WORDS: Numerical modelling of organs, liver, hypertonic solutions, bioimpedance, electroporation. 


\section{INTRODUCTION}

The liver has a distinctive blood supply in which blood comes from two different pathways. About $70 \%$ of blood comes from the portal vein whereas the remaining supply comes from the hepatic artery [1]. Both afferent vessels branch into venules and arterioles, eventually draining into the sinusoids, which are capillaries with fenestrations along their endothelial wall. These fenestrations allow the passage of small particles from the sinusoids to the hepatocytes across the interstitial space that surrounds the hepatocytes. Blood leaves the liver lobules through the central veins and it finally drains into the cava vein [2].

The dual blood supply of the liver and the presence of fenestrations in the sinusoids increase the likelihood of metastatic deposits in the liver [3]. Almost any primary cancer can spread to the liver and, when that happens, tumors commonly grow as scattered nodules [4]. About half of the patients with colorectal cancer develop hepatic metastases and less than $30 \%$ of those patients are suitable for surgical resection [5], thus portending a poor prognosis.

In addition to surgical resection, the current medical armamentarium includes a set of loco regional therapies for ablating malignant liver tissues which can be applied to patients who are non-surgical candidates because of comorbidity or extensive disease. These focal liver ablation techniques include percutaneous ethanol injection, radiofrequency ablation, high-intensity focused ultrasound, microwave ablation and cryosurgery [6]. These techniques, however, because of their focal nature, are not adequate for patients in which the number of scattered nodules is large $(>3)$ [7]. As an alternative, we have recently proposed a technique based on irreversible electroporation which may be able to simultaneously treat all nodules in the liver while sparing healthy liver tissue [8].

Electroporation is the phenomenon in which cell membrane permeability is increased by exposing the cell to high electric field pulses [9]. If the pulses are very intense, the permeabilization causes the cells to loss their homeostasis and die. This process is known as irreversible electroporation (IRE). IRE was proposed a few years ago as a focal ablation technique [10] and it has been clinically assayed [11]. Since electroporation does not involve thermal or chemical damage to the extracellular matrix, it allows to retain the structural integrity of the blood vessels and the nerves [12]. This fact allows treatment of tumors located close to critical structures which are unsuitable to be treated with other focal ablation techniques based on high-temperature. However, while IRE shows promising results treating non-resectable tumors [13], as a focal therapy, it is only recommended for treatment of less than three nodules with relatively small dimensions $(<5 \mathrm{~cm})[7]$. 
Interestingly, while healthy hepatocytes receive both arterial and venous blood, tumor nodules have a disorganized vascular structure, lacking sinusoids, which implies they are almost only supplied with arterial blood coming from the hepatic artery [14]. In view of the foregoing, we propose to inject a hypertonic saline solution with high electrical conductivity through the portal vein so that the overall conductivity of the healthy tissue increases whereas the conductivity in the tumor nodules is kept constant. Then, by applying high voltage pulses across two large electrode plates sandwiching the liver, a significantly larger field would be caused in the tumors than in the rest of the tissue, as described in the previous theoretical study [8]. In this way, it would be possible to cause electroporation of the tumor nodules while avoiding the effect in healthy parenchyma. This approach would have some major advantages with respect to the focal ablation techniques used in non-resectable tumor nodules. Namely, it would not be required to identify the exact position of the tumor nodules during the intervention and it would be possible to treat several tumor nodules at the same time making unnecessary to address them individually.

Prior to further development of the proposed technique, it is required to assess the capability to increase the electrical conductivity of the liver. We deem that the proposed liver electroporation technique will require increasing healthy liver conductivity by a minimum factor of 3 [8]. Here, in order to elucidate the expected behavior of conductivity during the procedure, a comprehensive mathematical model has been developed to predict both the temporal distribution of solute within the liver and the resulting electrical conductivity of the tissue.

Several studies have performed mathematical models of the liver to computationally assess the pharmacokinetic behavior of a defined drug or chemical agent $[15,16,17,18]$. These studies usually employed the so called physiologically based pharmacokinetic (PBPK) models which represent the anatomical and physiological structure of the organ by using interconnected fluidic compartments. However, as the employed drug concentrations are commonly low, these models neglected osmotic effects which are relevant in our case. On the other hand, hypertonic saline infusions have been used in fluid resuscitation for hemorrhagic patients [19] and some mathematical models have been developed aiming to determine the distribution at systemic level [20]. Here we fuse both modeling approaches in a novel model using the transport functions employed in the PBPK models in combination with the osmotic formulation from resuscitation models. 


\section{MATERIALS AND METHODS}

\subsection{Mathematical Model}

2.1.1. Liver Conductivity The electrical conductivity of a tissue at low frequency mainly depends on the extracellular solution conductivity and the structural morphology [21, 22]. Among the chemical species that constitute the extracellular body fluids, sodium and chlorine are the main contributors to the electrical conductivity. Consequently, here it was assumed that only sodium and chlorine ions contribute to the conductivity of the extracellular plasma [23].

By injecting a hypertonic $\mathrm{NaCl}$ solution into the bloodstream, the $\mathrm{NaCl}$ concentration of the plasma is altered. To determine the conductivity of plasma $\left(\sigma_{p}\right)$ at different $\mathrm{NaCl}$ concentrations $\left(C_{p}\right)$, experimental data reported on $\mathrm{NaCl}$ solutions [24] was fitted with an exponential function $\left(\mathrm{R}^{2}>0.99\right)$ :

The electrical conductivity of a tissue at low frequency mainly depends on the extracellular solution conductivity and the structural morphology $[21,22]$. Among the chemical species that constitute the extracellular body fluids, sodium and chlorine are the main contributors to the electrical conductivity. Consequently, here it was assumed that only sodium and chlorine ions contribute to the conductivity of the extracellular plasma [23].

By injecting a hypertonic $\mathrm{NaCl}$ solution into the bloodstream, the $\mathrm{NaCl}$ concentration of the plasma is altered. To determine the conductivity of plasma $\left(\sigma_{p}\right)$ at different $\mathrm{NaCl}$ concentrations $\left(C_{p}\right)$, experimental data reported on $\mathrm{NaCl}$ solutions [24] was fitted with an exponential function $\left(\mathrm{R}^{2}>0.99\right)$ :

$$
\sigma_{p}=30.22\left(1-e^{\frac{-C_{p}}{3135 \frac{m o l}{m^{3}}}}\right) 1.02^{\left(T-20^{\circ} C\right)} \frac{S}{m}
$$

The reported experimental data were obtained at $20^{\circ} \mathrm{C}$, therefore, an additional term was added for being able to assess the conductivity at body temperature $\left(T=37^{\circ} \mathrm{C}\right)$ taking into account the exponential conductivity grow of $2^{\circ} \mathrm{C}$ experienced by ionic solutions [25].

Physiological blood conductivity (about $0.65 \mathrm{~S} / \mathrm{m}$ ) differs substantially from that of the plasma (about $1.57 \mathrm{~S} / \mathrm{m}$ ). This difference is caused by the presence of red blood cells (RBCs) which, at low frequencies, can be considered as non-conductive elements [26]. Archies law [27] is extensively used in geology to assess the equivalent electric conductivity of composite materials [28]. Similarly, Archies law has also been employed to determine the electrical conductivity of biological tissues [26]. For a material composed by an aqueous medium with conductivity $\sigma_{\text {solv }}$ and non-conductive 
particles occupying a volume fraction $\left(\phi_{p}\right)$, the effective conductivity of the material $\left(\sigma_{e f f}\right)$ can be expressed as:

$$
\sigma_{e f f}=\sigma_{\text {solv }}\left(1-\phi_{p}\right)^{m}
$$

where $m$ is a factor dependent on the shape of particles. The blood is mainly a suspension of non conductive RBCs in solvent (plasma). Therefore, according to Equation (2), the electrical conductivity of blood in sinusoids $\left(\sigma_{s}\right)$ depends on its plasma conductivity $\left(\sigma_{p, s}\right)$ and the hematocrit value $\left(h_{s}\right)$. According to the shape of erythrocytes, a value $m=1.46$ has been reported [26], and thus:

$$
\sigma_{s}=\sigma_{p, s}\left(1-h_{s}\right)^{1.46}
$$

The same can be employed to compute the conductivity of the whole liver parenchyma. Using Equation (2) for the specific case of the liver parenchyma, the clusters of hepatic cells can be considered as the non-conductive particles which occupy a certain volume $\left(V_{c, h p}\right)$ of the parenchyma volume $\left(V_{P}\right)$. According to the cluster shape, the conductivity of the liver $\left(\sigma_{L}\right)$ can be approximated using a shape factor value $(m)$ of 1.67 [26]:

$$
\sigma_{L}=\sigma_{s i}\left(1-\frac{V_{c, h p}}{V_{P}}\right)^{1.67}
$$

In this case the solvent conductivity $\left(\sigma_{s i}\right)$ is assumed to be a mixture between the conductivities of blood at sinusoids $\left(\sigma_{s}\right)$ and the plasma at the interstitium $\left(\sigma_{p, h p}\right)$. For a material composed by n compounds with a specific electrical conductivity $\left(\sigma_{j}\right)$ and volume fraction $\left(\phi_{j}\right)$, and randomly oriented - which is the case of the parenchyma [29] - the effective conductivity can be expressed as [28]:

$$
\sigma_{e f f}=\prod_{n=1}^{n} \sigma_{j}^{\phi_{j}}
$$

Using Equation (5) it is possible to compute the effective conductivity of the composite material consisting of the sinusoids and the interstitial liquid according with their respective volumes $\left(V_{s}\right.$ and $\left.V_{p, h p}\right)$ :

$$
\sigma_{s i}=\sigma_{s}^{\frac{V_{s}}{V_{s}+V_{p, h p}}} \sigma_{p, h p}^{\frac{V_{p, h p}}{V_{s}+V_{p, h p}}}
$$


2.1.2. Compartmental Model A mathematical model was developed aiming at assessing both the fluid and solute movement within the liver. This model provides the parameters required to estimate the electrical conductivity of the liver parenchyma according to the formulation previously described.

Based on already reported models $[15,16,30]$, a compartment model was implemented (see Figure 1). The model has four macroscopic compartments. Two of them represent the intrahepatic portal and arterial vasculature and the other two represent the hepatic parenchyma which consists of sinusoids and hepatocellular plates.

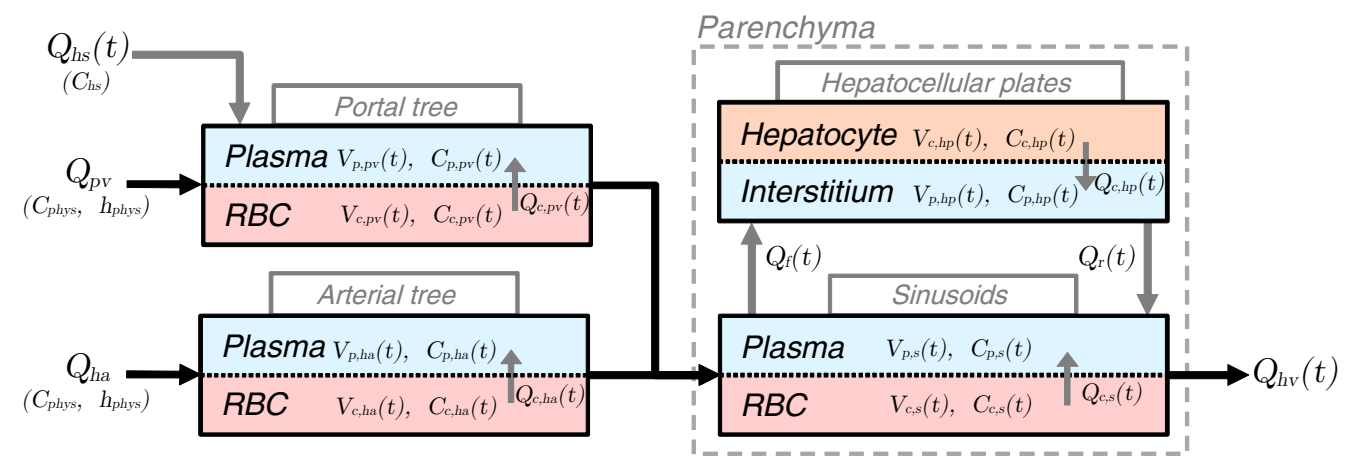

Figure 1. Representation of the compartmental model employed to simulate $\mathrm{NaCl}$ concentration. Composed by 8 sub-compartments, each one of them characterized by a volume $V_{x}, \mathrm{y}$ and an equivalent $\mathrm{NaCl}$ concentration $C_{x, y}$ where $x$ denotes the extracellular $(p)$ or intracellular $(c)$ liquid and $y$ denotes the macroscopic compartment ( $p v$ : Portal Vein, $h a$ : Hepatic Artery, $s$ : Sinusoids or $h p$ : Hepatocellular Plates). Black arrows represent blood flow (movement of plasma liquid and RBC) while grey arrows symbolize liquid flow.

The model describes three supplying flows: one of these symbolizes the hypersaline infusion and the other two represent the normal incoming blood flows. The hypersaline solution flow $\left(Q_{h s}\right)$, directly contributing to extracellular liquid in the portal vasculature, is modeled as a square pulse with a magnitude according to the flow employed during the experiments and with the corresponding constant concentration $\left(C_{h s}\right)$. Moreover, the blood supplies are characterized by their constant physiological flows $\left(Q_{p v}\right.$ and $\left.Q_{h a}\right)$, concentration $\left(C_{p h y s}\right)$ and hematocrit $\left(h_{p h y s}\right)$. Eventually blood exits from the sinusoids through the hepatic vein $\left(Q_{h v}=Q_{h s}+Q_{p v}+Q_{h a}\right)$.

In the sinusoidal macroscopic compartment, plasma with concentration $C_{p, s}$, crosses, through the capillary wall, into the interstitial space in the hepatocellular plates at filtration flow rate $Q_{f}$ and, at $Q_{r}$ flow rate, interstitial fluid with concentration $C_{p, h p}$ is reabsorbed by the sinusoids.

The filtration and reabsorption flows $\left(Q_{f}\right.$ and $\left.Q_{r}\right)$ between the sinusoids and the interstitial space of the hepatocellular plates are commonly included in models as constant parameters. Here, in contrast, are considered to be pressure dependent. It is well known that filtration flow in sinusoids 
is determined by the capillary filtration coefficient $\left(K_{f}\right)$ multiplied by the hydrostatic pressure difference between capillary and interstitium [31]. At the beginning of the sinusoid, closer form portal tract, sinusoidal pressure $\left(P_{s}\right)$ is higher than the interstitial one $\left(P_{i}\right)$ producing a filtration flow from the sinusoid to the interstitium.

$$
Q_{f}(t)=K_{f}\left(P_{s}(t)-P_{i}(t)\right)
$$

Moreover, closer to the hepatic vein, the capillary pressure $\left(P_{h v}\right)$ is lower than interstitial producing the reabsorption flow.

$$
Q_{r}(t)=K_{f}\left(P_{i}(t)-P_{h v}\right)
$$

According to Eqs. (7), (8) and the mass conservation, the filtration flow must be the same than the reabsorption flow, and this results in:

$$
Q_{f}(t)=Q_{r}(t)=K_{f}\left(P_{s}(t)-P_{h v}\right)
$$

For a defined capillary geometry and a constant blood flow, the resulting pressure at the entrance of the capillaries depends proportionally on fluid viscosity [32]. However, an acute pressure increase has been observed in the microvasculature when HS is injected into the blood stream [33]. This increase of pressure is attributed to the HS effect on RBCs [34].

It has been also reported a dynamic viscosity almost linearly dependent with osmolality [35]. Linearizing this reported data $\left(\mathrm{R}^{2}>0.99\right)$ at shear rate stress similar to the sinusoidal one (230 $\left.\mathrm{s}^{-1}\right)$ blood viscosity can be expressed as function of cellular $\mathrm{NaCl}$ concentration $\left(C_{c, s}\right)$ as:

$$
\mu_{s}(t)=4.59 \times 10^{-5} \frac{\mathrm{Nms}}{\mathrm{mol}} C_{c, s}(t)-3.49 \times 10^{-3} \frac{\mathrm{Ns}}{\mathrm{m}^{2}}
$$

Although the increase of viscosity affects the whole liver vasculature, the apparent viscosity in large vasculature (i.e. hepatic artery, portal vein and hepatic veins) does not increase as much as in the sinusoids [35]. Therefore, here it is only considered the viscosity dependence effect over the sinusoids.

This pressure can be estimated according to the hepatic vein vasculature pressure $\left(P_{h v, p h y s}\right)$, the sinusoidal flow resistance $\left(R_{s, p h y s}\right)$ and the viscosity $\left(\mu_{p h y s}\right)$ at physiological state, and along with 
the current blood flow through sinusoids $\left(Q_{s}=Q_{h v}-Q_{r}\right)$ and the instantaneous blood viscosity $\left(\mu_{s}\right)$.

$$
\begin{gathered}
R_{s, p h y s}=\frac{P_{s, p h y s}-P_{h v, p h y s}}{Q_{s, p h y s}} \\
P_{s}(t)=P_{h v, p h y s}+Q_{s}(t) R_{s, p h y s} \frac{\mu_{s}(t)}{\mu_{p h y s}}
\end{gathered}
$$

The amount of solute used in pharmacological studies is usually low. Therefore, the commonly employed PBPK models of the liver do not consider osmotic flow between compartments. However, as the HS osmolarity highly differs from the physiological one, the osmotic equilibrium plays an important role in the case modeled here. Thus, each one of the macroscopic compartments is divided into two sub-compartments, one of them representing the extracellular liquid and the other representing the liquid confined within the cells. A difference in osmolarity between plasma and cellular sub-compartments leads to the water movement across the cell membrane $\left(Q_{c}\right)$ trying to reach equilibrium. According to mathematical models used in the resuscitation field [20], the flow of water from cells to plasma $\left(Q_{c}\right)$ depends on its membrane hydraulic conductivity $\left(L_{c}\right)$, the cells plasma surface area $\left(S_{c}\right)$ - considered as constant - and the osmotic pressure difference between both compartments $(\Delta \Pi)$.

$$
Q_{c}(t)=L_{c} S_{c} \Delta \Pi
$$

Although the ions within the cell differ from those found in the extracellular space, the osmolarity of both compartments is kept at the same value $\left(308 \mathrm{~mol} / \mathrm{m}^{3}\right)$. Therefore, for the sake of simplicity, as no exchange of solutes is assumed across the cell membrane, here the intracellular concentration is defined as a $\mathrm{NaCl}$ concentration although, in reality, the intracellular content differs from a $\mathrm{NaCl}$ solution. In other words, $C_{c}$ indicates the concentration of $\mathrm{NaCl}$ that would produce the same osmolarity within the cell. $C_{c}$ does not represent the actual concentration of intracellular species but it is proportional to it. Such simplification is just used for computing the osmotic pressure.

$$
\Delta \Pi=R T\left(2 C_{p}-2 C_{c}\right)
$$


The osmotic pressure difference $(\Delta \Pi)$ between two compartments is defined in Equation (14) by their osmolarity (two times the concentration in case of a $\mathrm{NaCl}$ solution), the temperature ( $T=310$ $\mathrm{K})$ and the gas constant $\left(R=0.06236 \mathrm{~m}^{3} \cdot \mathrm{mmHg} /(\mathrm{K} \cdot \mathrm{mol})\right)$.

The model computes the time course of the concentration in each sub-compartment. The liquid and solute exchanges are formalized by the physiological parameters shown in Table I and by the following differential equations derived from the conservation of mass. Runge-Kutta method was employed (MatLab R2014b, MathWorks, Natick, MA, USA) to solve the resulting system of equations:

Table I. Physiological parameters employed in the model.

\begin{tabular}{|c|c|c|c|}
\hline Symbol & Description & Value & Source \\
\hline$C_{\text {phys }}$ & Physiological $\mathrm{NaCl}$ concentration & $154 \mathrm{~mol} / \mathrm{m}^{3}$ & [20] \\
\hline$Q_{p v}$ & Flux of blood through portal vein & $24.0 \mathrm{ml} /(\mathrm{min} \cdot \mathrm{kg})$ & [36] \\
\hline$Q_{h a}$ & Flux of blood through hepatic artery & $8.4 \mathrm{ml} /(\min \cdot \mathrm{kg})$ & [36] \\
\hline$K_{f}$ & Filtration coefficient of sinusoids wall & $3 \mathrm{ml} /(\mathrm{min} \cdot \mathrm{mmHg} \cdot \mathrm{kg})$ & [31] \\
\hline$P_{s, p h y s}$ & Physiological pressure at sinusoids & $4.4 \mathrm{mmHg}$ & [37] \\
\hline$P_{h v, p h y s}$ & Physiological pressure at the hepatic vein & $1.5 \mathrm{mmHg}$ & [37] \\
\hline$h_{\text {phys }}$ & Physiological hematocrit & $45 \%$ & [38] \\
\hline$V_{L}$ & Liver volume & $30.3 \mathrm{ml} / \mathrm{kg}$ & [36] \\
\hline$V_{p v}$ & Portal vasculature volume & $13.3 \times 10^{-2} V_{L}$ & See Appendix \\
\hline$V_{h a}$ & Hepatic artery vasculature volume & $4.6 \times 10^{-2} V_{L}$ & See Appendix \\
\hline$V_{h v}$ & Hepatic vein vasculature volume & $16.2 \times 10^{-2} V_{L}$ & See Appendix \\
\hline$V_{P}$ & Parenchyma volume & $65.9 \times 10^{-2} V_{L}$ & $V_{L}-V_{p v}-V_{h a}-V_{h v}$ \\
\hline$V_{c, h p}$ & Hepatocyte volume at physiological state & $77.8 \times 10^{-2} V_{P}$ & [39] \\
\hline$V_{p, h p}$ & Interstitial volume at physiological state & $4.9 \times 10^{-2} V_{P}$ & [39] \\
\hline$V_{s}$ & Sinusoidal volume & $10.6 \times 10^{-2} V_{P}$ & [39] \\
\hline$\rho_{L}$ & Liver density & $1070 \mathrm{~kg} / \mathrm{m}^{3}$ & {$[40]$} \\
\hline$S_{c, p v}$ & Portal RBC membrane surface & $859.5 \mathrm{~cm}^{2} / \mathrm{ml} V_{L}$ & [20] $h_{p h y s} V_{p v}$ \\
\hline$L_{c, p v}$ & Membrane hydraulic conductivity & $7.2 \times 10^{-7} \mathrm{ml} /\left(\mathrm{min} \cdot \mathrm{mmHg} \cdot \mathrm{cm}^{2}\right)$ & [20] \\
\hline$S_{c, h a}$ & Arterial RBC membrane surface & $297.3 \mathrm{~cm}^{2} / \mathrm{ml} V_{L}$ & [20] $h_{\text {phys }} V_{h a}$ \\
\hline$L_{c, h a}$ & Membrane hydraulic conductivity & $7.2 \times 10^{-7} \mathrm{ml} /\left(\mathrm{min} \cdot \mathrm{mmHg} \cdot \mathrm{cm}^{2}\right)$ & {$[20]$} \\
\hline$S_{c, s}$ & RBC membrane surface in sinusoids & $451.5 \mathrm{~cm}^{2} / \mathrm{ml} V_{L}$ & {$[20] h_{p h y s} V_{s}$} \\
\hline$L_{c, s}$ & Membrane hydraulic conductivity & $7.2 \times 10^{-7} \mathrm{ml} /\left(\mathrm{min} \cdot \mathrm{mmHg} \cdot \mathrm{cm}^{2}\right)$ & {$[20]$} \\
\hline$S_{c, h p}$ & Hepatocyte-interstitium surface & $337.9 \mathrm{~cm}^{2} / \mathrm{ml} V_{L}$ & See Appendix \\
\hline$L_{c, h p}$ & Membrane hydraulic conductivity & $1.3 \times 10^{-6} \mathrm{ml} /\left(\mathrm{min} \cdot \mathrm{mmHg} \cdot \mathrm{cm}^{2}\right)$ & [20] \\
\hline
\end{tabular}

$$
\begin{gathered}
V_{p, p v}(t) \frac{d C_{p, p v}(t)}{d t}=C_{h s} Q_{h s}(t)+C_{p h y s} Q_{p v}\left(1-h_{p h y s}\right) \\
-C_{p, p v}(t)\left(\left(Q_{h s}(t)+Q_{p v}\right)\left(1-h_{p v}(t)\right)+Q_{c, p v}(t)\right) \\
V_{c, p v}(t) \frac{d C_{c, p v}(t)}{d t}=C_{p h y s} Q_{p v} h_{p h y s}-C_{c, p v}(t)\left(\left(Q_{h s}(t)+Q_{p v}\right) h_{p v}(t)-Q_{c, p v}(t)\right) \\
V_{p, h a}(t) \frac{d C_{p, h a}(t)}{d t}=C_{p h y s} Q_{h a}\left(1-h_{p h y s}\right)-C_{p, h a}(t)\left(Q_{h a}\left(1-h_{h a}(t)\right)+Q_{c, h a}(t)\right)
\end{gathered}
$$




$$
\begin{gathered}
V_{c, h a}(t) \frac{d C_{c, h a}(t)}{d t}=C_{p h y s} Q_{h a} h_{p h y s}-C_{p, h a}(t)\left(Q_{h a} h_{h a}(t)-Q_{c, h a}(t)\right) \\
V_{p, s}(t) \frac{d C_{p, s}(t)}{d t}=C_{p, p v}(t)\left(Q_{h s}+Q_{p v}\right)\left(1-h_{p v}\right)+C_{p, h a}(t) Q_{h a}\left(1-h_{h a}(t)\right) \\
+C_{p, h p}(t) Q_{r}(t)-C_{p, s}(t) Q_{f}(t)-C_{p, s}(t)\left(Q_{h v}\left(1-h_{s}(t)\right)+Q_{c, s}(t)\right) \\
V_{c, s}(t) \frac{d C_{c, s}(t)}{d t}=C_{c, p v}\left(Q_{h s}(t)+Q_{p v}\right) h_{p v}(t)+C_{c, h a}(t) Q_{h a} h_{h a}(t) \\
-C_{c, s}(t)\left(Q_{h v} h_{s}(t)-Q_{c, s}(t)\right) \\
V_{p, h p}(t) \frac{d C_{p, h p}(t)}{d t}=C_{p, s}(t) Q_{f}-C_{p, h p}(t)\left(Q_{r}(t)+Q_{c, h p}(t)\right) \\
\frac{d V_{c, x}(t)}{d t}=-Q_{c, x} \\
\frac{d V_{p, x}(t)}{d t}=Q_{c, x}
\end{gathered}
$$

\subsection{In Vivo Pilot Study}

2.2.1. Animal Model All actions in this study were performed in accordance with the protocol approved by the Ethical Commission of the Universitat Autònoma de Barcelona (authorization number CEEAH 2205/ DMAH 7633) following the European Directive 2010/63/EU on the protection of animals used for scientific purposes. A total of 5 procedures - one in each animal - were performed under general anesthesia on Landrace pigs (mean weight $57 \mathrm{~kg}$ ).

2.2.2. Procedure Preoperative care and anesthesia were provided by fully trained veterinary staff. The anesthetic induction phase was performed with propofol (4 mg/kg I.V.) and maintained with isoflurane from 1.5 to $2 \%$ and oxygen $100 \%$ mixture once the animal was endotracheally intubated. Oxygen saturation, arterial blood pressure, heart rate and capnography were monitored using a multiparametric monitor. 
By midline laparotomy, after dissection of the hepatoduodenal ligament, extrahepatic portal vein catheterization was performed in order to deliver either a hypersaline solution $(\mathrm{NaCl}$ at $20 \%)$ or an isotonic solution $(\mathrm{NaCl} 0.9 \%)$ in the control case. After exposure, the portal vein was dissected free and cannulated through a purse-string suture placed just cranial (approximately $1 \mathrm{~cm}$ ) to the entry point of the cranial pancreaticoduodenal vein with a simple silastic catheter (dropper tube). The catheter was advanced cranial to a point just proximal to the main portal division and secured in place via the purse-string suture and a single stay suture. The solution volume employed in the procedures was injected by using a dropper while infusion durations were measured with a stop watch. Aiming to explore the conductivity dependence in both the amount of solution injected and the flow rate, different values were employed (see Table II).

Table II. Injection parameters employed in animal experiments

\begin{tabular}{ccccc}
\hline Animal & $\mathrm{NaCl}(\%)$ & Volume $(\mathrm{ml})$ & Duration $(\mathrm{s})$ & Flow $(\mathrm{ml} / \mathrm{min})$ \\
\hline$\# 1$ & 20 & 100 & 113 & 53 \\
$\# 2$ & 20 & 100 & 52 & 115 \\
$\# 3$ & 20 & 120 & 60 & 120 \\
$\# 4$ & 20 & 200 & 70 & 171 \\
$\# 5$ & 0.9 & 500 & 120 & 250 \\
\hline
\end{tabular}

Although the planned therapeutic technique involves hepatic vascular isolation, such strategy was not employed during this pilot study aiming to simplify the experimental setup. However, since rapid infusion of a high amount of HS could cause severe damage to the animal and a high disturbance of the normal blood flow [41] which could distort the study, it was decided to adopt a relatively simple approach to prevent those consequences. Specifically, in order to minimize the possible ionic and osmotic imbalance at systemic level caused by the HS, as recommended to manage hypernatremia [42], distilled water was simultaneously injected at the cava vein. Using an additional catheter with the same cannulation technique immediately cranial to entry point of the right renal vein and advanced cranial two centimeters. The amount of injected water was ten times the hypersaline volume in order to restore the $\mathrm{NaCl}$ concentration in the systemic blood.

2.2.3. Conductivity Measurement It is possible to measure the impedance of a living tissue portion by inducing a known current through a pair of electrodes while measuring the resulting voltage drop across them. In the presented study, the electrode setup consisted of two printed circuit boards (PCBs) including a circular gold coated electrode (20 mm diameter). The PCBs were mounted on a pincer clip so that the electrodes were securely placed at opposite sides of a hepatic lobule forming a fixed geometry. The electrodes were placed at a distal section of the lobule to avoid the potential 
influence of large intrahepatic blood vasculature. Electrical impedance was measured at a rate of five sweeps per second. The spectrogram consisted of six frequencies from 10 to $100 \mathrm{kHz}$. The excitation signal was a sinusoidal signal with $1 \mathrm{~V}$ amplitude applied to the tissue through a $2 \mathrm{k} \Omega$ resistor in order to limit the peak current to a maximum of $500 \mu \mathrm{A}$. Both the injected current and the voltage drop over the tissue were simultaneously collected to compute the real and imaginary parts of the impedance using a data acquisition board (NI USB-6212, National Instruments, Austin, TX, USA) controlled by a virtual instrument (Labview 8.1, National Instruments, Austin, TX, USA). The Cole model for bioimpedance can be employed to characterize the measured impedance $(Z(f))$ spectrogram with only four parameters: the hypothetical resistance at infinite $\left(R_{\infty}\right)$ and zero $\left(R_{0}\right)$ frequencies, the characteristic time constant $\tau$ and the dimensionless parameter $\alpha$ [43].

$$
Z(f)=R_{\infty}+\frac{R_{0}-R_{\infty}}{1+(j 2 \pi f \tau)^{\alpha}}
$$

This equation was employed here to determine the hypothetical impedance magnitude at 0 $\mathrm{Hz}$ automatically fitting the equation (MatLab R2014b, MathWorks, Natick, MA, USA) to the experimental data by minimizing the least squares error.

Once the impedance at $0 \mathrm{~Hz}$ was obtained in Equation (25), the conductivity at this frequency $\left(\sigma_{0}\right)$ was calculated according to the geometric cell constant $(K)$ of the measurement system as computed by means of a model based on Finite Element Method [43].

$$
\sigma_{0}=\frac{1}{R_{0} K}
$$

\section{RESULTS}

According to the described formulation and the parameters of the Table I, the physiological electrical conductivities at $37^{\circ} \mathrm{C}$ of the plasma, blood and liver are $2.03 \mathrm{~S} / \mathrm{m}, 0.85 \mathrm{~S} / \mathrm{m}$ and $0.09 \mathrm{~S} / \mathrm{m}$ respectively.

Figure 2(a) shows the estimated evolution of the liver conductivity over the time. The simulation results show a fast increase at the beginning of the infusion mainly due to the presence of high conductivity medium in sinusoids (Figure 2(b)). Following that, the contribution of sinusoidal medium remains constant while the interstitial contribution - due to the filtration process and hepatocyte shrink - keeps growing until HS injection stops (Figure 2(c)). At this point, the rapid decrease in liver conductivity can be attributed to the replacement of the high conductivity sinusoidal 
content by systemic blood. Meanwhile, the high conductivity plasma at the interstitial space is arrested for a longer period of time, producing a remaining conductivity offset which requires longer periods to return to the physiological values.
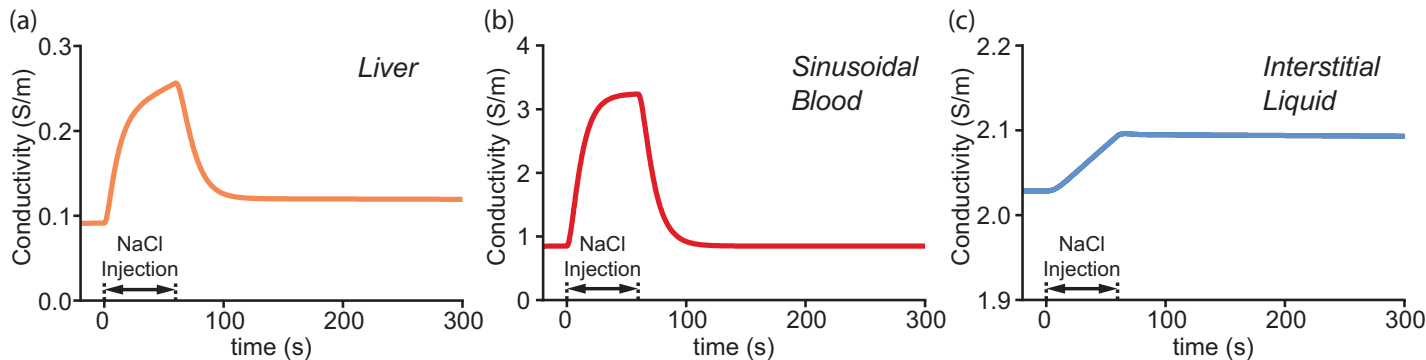

Figure 2. Temporal evolution of the computed electrical conductivity. Assessment of conductivity of the liver (a), the sinusoidal blood (b) and the interstitial liquid (c). Plots correspond with an injection of $2 \mathrm{ml} / \mathrm{kg}$ of $20 \% \mathrm{NaCl}$ at $2 \mathrm{ml} /(\mathrm{min} \cdot \mathrm{kg})$.

For an injected saline concentration of $20 \%$, the model has two independent input parameters corresponding to the flow rate and the total amount of solution introduced. The effect of each of those inputs over the temporal evolution of the conductivity is shown in Figure 3. It can be observed that the maximum electrical conductivity achieved at the end of the HS injection highly depends on both the flow and the volume.
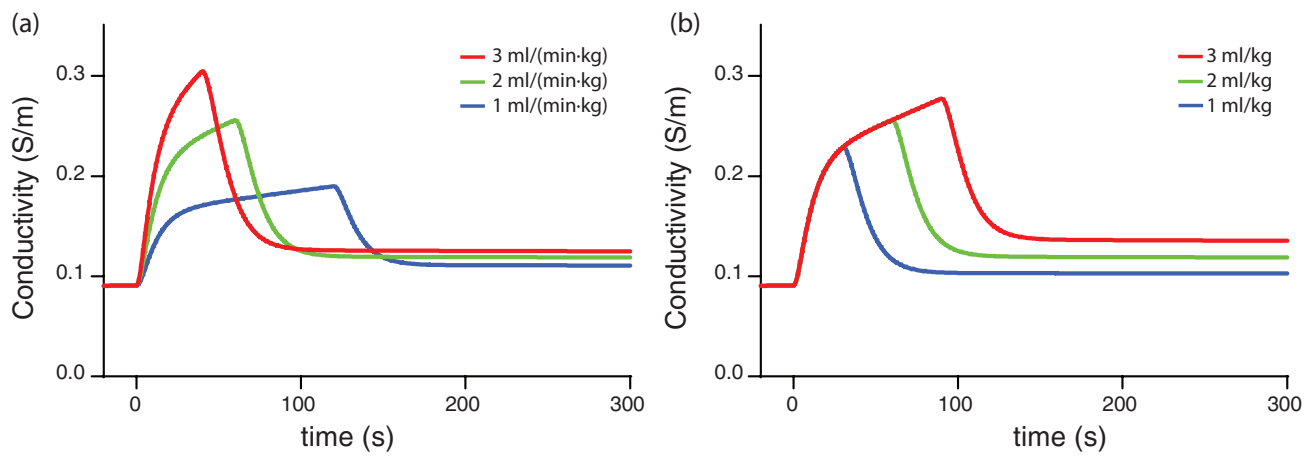

Figure 3. Effect of flow rate and volume of injected saline on the temporal evolution of electrical conductivity in the liver. Plots of (a) correspond with a fixed volume of $2 \mathrm{ml} / \mathrm{kg}$ of $20 \% \mathrm{NaCl}$, while plots in (b) correspond with a constant flow rate of $2 \mathrm{ml} /(\mathrm{min} \cdot \mathrm{kg})$.

About the in vivo pilot study, it is important to note that only the electrical conductivity of the liver can be measured with the employed setup. The baseline electrical conductivity of the liver was very similar in all the animals $(0.11 \pm 0.02 \mathrm{~S} / \mathrm{m})$. As observed in computer simulations, conductivity progress always peaked just at the end of the injection. The maximum peak value was $0.44 \mathrm{~S} / \mathrm{m}$ (animal \#4) and corresponded with an injection of $3.8 \mathrm{ml} / \mathrm{kg}$ at $3.3 \mathrm{ml} /(\mathrm{min} \cdot \mathrm{kg}$ ) (Figure 4(a)). Injection of a highly concentrated $\mathrm{NaCl}$ solution through portal vein produced a rapid increase of conductivity with time until the injection stops. At this point, a portion of the achieved conductivity 
increase slowly receded exponentially with time. However, the liver conductivity remained at a higher value than the basal one. In the control animal (animal \#5), in which physiological saline solution $(\mathrm{NaCl} 0.9 \%)$ was injected, the conductivity of the liver did not show any variation, remaining at basal level (Figure 4(b)).
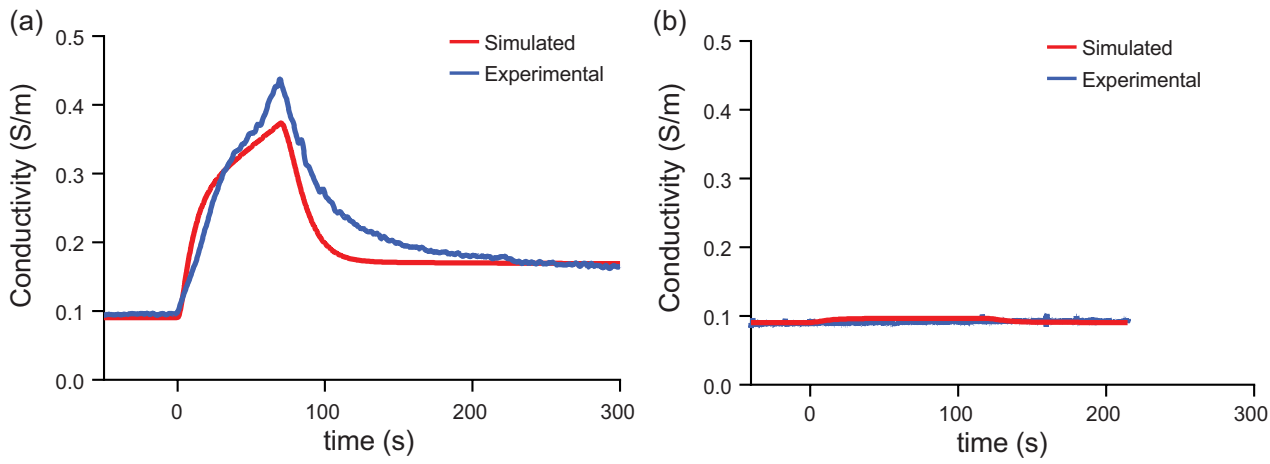

Figure 4. Temporal evolution of liver conductivity from simulations and experiments. (a): temporal evolution in the case of an injection of $3.8 \mathrm{ml} / \mathrm{kg}(20 \% \mathrm{NaCl})$ at a flow rate of $3.3 \mathrm{ml} /(\mathrm{min} \cdot \mathrm{kg})$. (b): temporal evolution in case of injecting physiological saline solution $(0.9 \% \mathrm{NaCl})$ which served as a control test.

Assessing with the model the resulting conductivity peak for a set of volumes and flows combinations, it is possible to obtain tridimensional representation of the peak conductivity value within a range of flow rates and volumes (Figure 5). Those values can be compared to the ones obtained during the in vivo pilot study in order to assess the goodness of fit of the proposed model in terms of relative error (Table III).

Table III. Conductivity values during experimental procedures and comparison with computer simulations.

\begin{tabular}{|c|c|c|c|c|c|c|c|c|}
\hline \multirow{2}{*}{ Animal } & \multirow{2}{*}{$\begin{array}{c}\text { Volume } \\
20 \% \mathrm{NaCl} \\
(\mathrm{ml} / \mathrm{kg})\end{array}$} & \multirow{2}{*}{$\begin{array}{c}\text { Flow Rate } \\
(\mathrm{ml} /(\mathrm{min} \cdot \mathrm{kg}))\end{array}$} & \multicolumn{2}{|c|}{ Simulated } & \multicolumn{2}{|c|}{ Experimental } & \multirow{2}{*}{$\begin{array}{c}\text { Basal } \\
\text { Conductivity } \\
\text { Error }(\%)\end{array}$} & \multirow{2}{*}{$\begin{array}{c}\text { Peak } \\
\text { Conductivity } \\
\text { Error }(\%)\end{array}$} \\
\hline & & & $\begin{array}{c}\text { Basal } \\
\text { Conductivity } \\
(\mathrm{S} / \mathrm{m})\end{array}$ & $\begin{array}{c}\text { Peak } \\
\text { Conductivity } \\
(\mathrm{S} / \mathrm{m})\end{array}$ & $\begin{array}{c}\text { Basal } \\
\text { Conductivity } \\
(\mathrm{S} / \mathrm{m})\end{array}$ & $\begin{array}{c}\text { Peak } \\
\text { Conductivity } \\
(\mathrm{S} / \mathrm{m})\end{array}$ & & \\
\hline$\# 2$ & 1.9 & 2.2 & 0.091 & 0.266 & 0.109 & 0.178 & 16.5 & 49.7 \\
\hline \#3 & 2.6 & 2.6 & 0.091 & 0.304 & 0.137 & 0.295 & 33.8 & 3.2 \\
\hline \#4 & 3.8 & 3.3 & 0.091 & 0.373 & 0.093 & 0.444 & 2.5 & 15.8 \\
\hline
\end{tabular}

${ }^{*} 5.5 \mathrm{ml} / \mathrm{kg} 0.9 \% \mathrm{NaCl}$

\section{DISCUSSION}

In this study, a mathematical model was developed aiming to assess the electrical conductivity of the liver once hypertonic saline solution is introduced through portal vasculature. Our main purpose was to formulate a mathematical model useful to continue with the development of a novel multi-nodule ablation technique based on electroporation. 


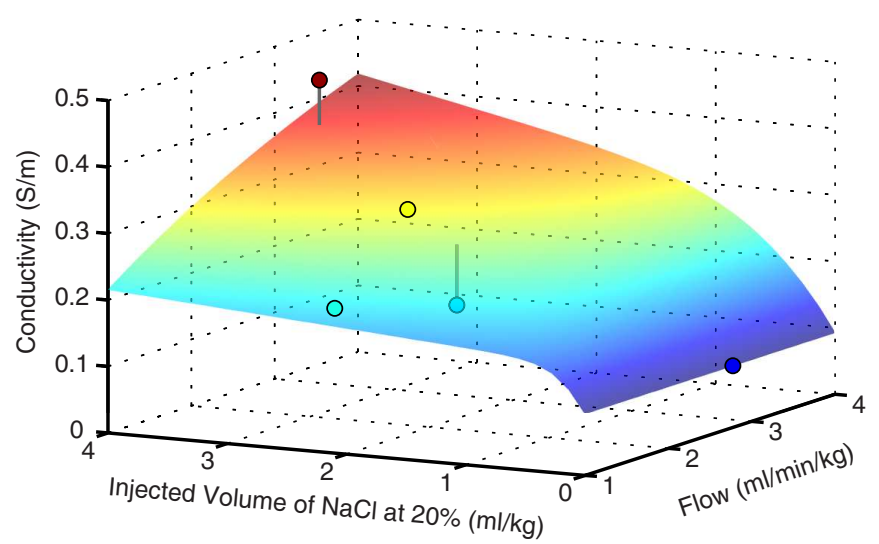

Figure 5. Dependence of conductivity peak on volume and flow of injected saline $(20 \% \mathrm{NaCl})$. The surface represents the simulated values from the proposed mathematical model, while circles represent the five experimental results from the in vivo model. Gray lines denote the absolute error value between the values predicted by the model and those experimentally observed.

Hypertonic saline solution has been extensively used in resuscitation of patients with traumatic brain injury [44]. Using $7.2 \% \mathrm{NaCl}$ intravenously injected, it has been reported a safety dosage of $5 \mathrm{ml} / \mathrm{kg}$ of body weight without inducing hypernatremia [45]. Accordingly to this safety value, the maximum dosage at $20 \% \mathrm{NaCl}$ would be $1.8 \mathrm{ml} / \mathrm{kg}$. This amount is slightly below the maximum doses tried and proposed here for significantly increasing liver conductivity. Therefore, some sort of countermeasure is required for safety in order to avoid severe pathophysiological effects, such as hyperchloremic acidosis or dilated coagulopathy [46]. For the presented pilot study parallel downstream administration of distilled water was a feasible and effective countermeasure to avoid acute dysfunctions at systemic level that could distort our study. However, the proposed electroporation technique should include a sort of liver isolation similar to the employed in the isolated hepatic perfusion (IHP) therapies [47]. That is, we anticipate extracting the hypertonic solution as it leaves the liver.

Besides systemic effects, another source of concern would be the potential tissue damage produced on the liver tissue itself due to the hypersaline injection. Nevertheless, according to literature, a direct intratisular injection of hypersaline solution at very high dosage $(36.5 \% \mathrm{NaCl})$ is required to produce small tissue damage [48]. And according to the presented model, at the maximum dosage employed during the in vivo experiments, interstitial concentration hardly reaches a concentration of $1 \% \mathrm{NaCl}$. Therefore hepatocellular damage due to portal injection of the hypersaline solution is not anticipated.

The developed model accounts for the increased blood viscosity in the sinusoids due to the high osmolarity of the HS. Such increase in viscosity raises the hydrostatic pressure in the sinusoids 
which in turn causes an excess of filtration/reabsorption flow thereby rapidly flushing out the original interstitial fluid. This makes the presented modeling approach not only useful for the particular case of portal HS injection but also for assessing the distribution of other hypertonic solutions such as high concentration contrasts $[49,50]$.

According to the employed methodology, the physiological conductivity for blood would be $0.85 \mathrm{~S} / \mathrm{m}$, which is larger than the value commonly reported (about $0.65 \mathrm{~S} / \mathrm{m}$ ) [51] but close to the reported value in other experimental studies $(0.76 \mathrm{~S} / \mathrm{m})$ [52]. Physiological values for liver conductivity at low frequency found in literature range widely from very low values $(0.03 \mathrm{~S} / \mathrm{m})$ [53] to larger values $(0.126 \mathrm{~S} / \mathrm{m})$ [54]. The physiological conductivity predicted by the model is $0.09 \mathrm{~S} / \mathrm{m}$, which is close to the commonly reported value $(0.075 \mathrm{~S} / \mathrm{m})$ [43] and within the range of the basal conductivities, $0.11 \pm 0.02 \mathrm{~S} / \mathrm{m}$ (mean $\pm \mathrm{SD}$ ), obtained during the in vivo experiments reported here.

In agreement with the results of the experimental study, the developed model is able to predict the maximum conductivity with a $14.6 \%$ average relative error once HS is portally injected. These results, together with the consistency of the basal conductivity results reported in the literature (previous paragraph), indicate the goodness of the model for our purposes. However, we deem the model could be further improved. In particular, we consider that a severe limitation of the model is that it assumes constant macroscopic volumes. In contrast, it is known that the liver acts as an expandable blood reservoir [55] and its compliance could hence play an important role. This factor should be incorporated in future models in order to predict the expected conductivity even in pathological states such as cirrhotic or fibrotic in which mechanical properties of the tissue differs from the normal ones.

\section{CONCLUSIONS}

A mathematical model able to assess the resulting electrical conductivity of the liver when hypertonic saline solution is portally injected is presented. The model is able to estimate the timespace distribution of the solute within the different physiological compartments of the organ.

The results show that the developed model is able to predict with an average error of $14.6 \%$ the maximum liver conductivity observed during the pilot in vivo study. The experiments were conducted on pigs where liver electrical conductivity was measured during injection of $\mathrm{NaCl}$ at $20 \%$ through the portal vein at different volumes and flow rates. The goodness of the model would 
make it useful not only for the particular case of hypersaline injection but also for other non-isotonic solutions injections such as high concentration contrasts.

Both mathematical modelization and pilot in vivo results show the feasibility of increasing up to four times the conductivity of the healthy liver. These results encourage further development of the multi-nodule ablation technique based on electroporation we have proposed.

\section{CONFLICT OF INTEREST}

All authors declare that they do not have conicts of interest.

\section{APPENDIX}

\section{Estimation of physiological parameters}

Most of the parameters employed in the model (Table I) were extracted directly from the literature. However, some of the required parameters could not be found in past experimental studies and had to be estimated under some assumptions. In here it is described the processes for obtaining those estimations

First, the model requires the physiological volume of blood in each vascular tree (i.e. portal, arterial and venous vasculature). Dimensional measurements of the intrahepatic vasculature were reported in [56] by using casting resin. Based on these data - simplifying vessels as tubes - the total volume of each tree was calculated $(81.6 \mathrm{ml}$ for the arterial tree, $236.7 \mathrm{ml}$ for the portal tree and $288.0 \mathrm{ml}$ for the venous tree). According to the liver weight employed in the experimental study $(1.9 \mathrm{~kg})$ and the liver density $\left(1070 \mathrm{~kg} / \mathrm{m}^{3}\right.$ [40]) the vasculature volume ratios with respect to the total liver volume were calculated: $4.6 \%$ for the arterial tree, $13.3 \%$ for portal tree and $16.2 \%$ for the venous tree.

Second, no data was found regarding the contact surface $\left(S_{c, h p}\right)$ between the hepatocytes and the interstitial space. Considering the sinusoids as tubes of radius $r_{s}(5 \mu \mathrm{m}$ [37]), it was possible to calculate the total length of the sinusoids per unit of liver volume $\left(8.89 \times 10^{8} \mathrm{~m} / \mathrm{m}^{3}\right)$ required to hold the sinusoidal blood (10.6\% of parenchyma volume $\left.\left(V_{P}\right)[39]\right)$. The interstitial space was then modeled as an annular region around the sinusoids with their same length. The width of this region $(1.05 \mu \mathrm{m})$ was determined by the physiological interstitial volume $\left(V_{p, h p}\right)(4.9 \%$ of parenchyma volume [39]). Finally, the interface between the hepatocytes and the interstitium per 
unit of liver volume was assumed to be the outer surface of the cylinder formed by the sinusoids and the surrounding interstitial ring resulting in $337.9 \mathrm{~cm}^{2} / \mathrm{ml}$.

\section{Nomenclature}

The mathematical model described in this work uses several parameters for its definition. The employed nomenclature for this parameters follows the same structure. The main symbol (Table A1) indicates the defined magnitude for the parameter, whereas the subscript or subscripts (Table A2) indicate the anatomical location or state which is intended to be represented. Table A3 lists the individual description for each of the parameters employed in the model.

Table A1. Description of magnitudes used in the model

\begin{tabular}{ll}
\hline Symbol & Description \\
\hline$C$ & Concentration of solute \\
$h$ & hematocrite \\
$K_{f}$ & Capillary filtration coefficient \\
$L_{c}$ & Membrane Hydraulic conductivity \\
$P$ & Hydrostatic pressure \\
$Q$ & Flow \\
$R$ & Flow resistance \\
$S_{c}$ & Surface area between cells and extracellular plasma \\
$T$ & Tempreature \\
$V$ & Volume \\
$\mu$ & Blood viscosity \\
$\Pi$ & Osmotic pressure \\
$\rho$ & Density \\
$\sigma$ & Electrical Conductivity \\
\hline
\end{tabular}

Table A2. Description of subscripts used in the model

\begin{tabular}{ll}
\hline Subscript & Description \\
\hline$L$ & Liver \\
$P$ & Parenchyma \\
$h a$ & Hepatic artery \\
$h p$ & Hepatocellular plates \\
$p v$ & Portal vein \\
$h v$ & Hepatic vein \\
$s$ & Sinusoids \\
$h s$ & Hipertonic solution \\
$c$ & Cells \\
$p$ & Plasma \\
$p h y s$ & Physiological \\
\hline
\end{tabular}


Table A3. Description of parameters used in the model

\begin{tabular}{|c|c|}
\hline Symbol & Description \\
\hline$C_{c, h a}$ & Concentration in rbc at hepatic artery \\
\hline$C_{c, h p}$ & Concentration in hepatocites at hepatocellular plate \\
\hline$C_{c, p v}$ & Concentration in rbc at portal vein \\
\hline$C_{c, s}$ & Concentration in rbc at sinusoids \\
\hline$C_{c}^{c, s}$ & Concentration of solute at the cells \\
\hline$C_{h s}$ & Concentration of Hipertonic solution \\
\hline$C_{p, h a}$ & Concentration of plasma at hepatic artery \\
\hline$C_{p, h p}^{p, n a}$ & Concentration of plasma at hepatocellular plate \\
\hline$C_{p, p v}^{p, n p}$ & Concentration of plasma at portal vein \\
\hline$C_{p, s}$ & Concentration of plasma at sinusoids \\
\hline$C_{p}$ & Concentration of solute in plasma \\
\hline$C_{\text {phys }}$ & Physiological concentration \\
\hline$h_{h a}$ & Hematocrite value at hepatic artery \\
\hline$h_{\text {phys }}$ & Hematocrite value at physiological state \\
\hline$h_{p v}$ & Hematocrite value at portal vein \\
\hline$h_{s}$ & Hematocrite value at sinusoids \\
\hline$L_{c, h a}$ & Membrane hydraulic conductivity at hepatic artery \\
\hline$L_{c, h p}$ & Membrane hydraulic conductivity at hepatocellular plates \\
\hline$L_{c, p v}$ & Membrane hydraulic conductivity at portal vein \\
\hline$L_{c, s}$ & Membrane hydraulic conductivity at sinusoids \\
\hline$P_{h v, p h y s}$ & Hydrostatic pressure at the beginning of the hepatic vein at physiological state \\
\hline$P_{h v}$ & Hydrostatic pressure at the beginning of the hepatic vein \\
\hline$P_{i}$ & Hydrostatic pressure at the interstitial space \\
\hline$P_{s, p h y s}$ & Hydrostatic pressure at the beginning of the sinusoids at physiological state \\
\hline$P_{s}$ & Hydrostatic pressure at the beginning of the sinusoids \\
\hline$Q_{c, h a}$ & Flow of water leaving from cells at hepatic artery \\
\hline$Q_{c, h p}$ & Flow of water leaving from cells at hepatocellular plate \\
\hline$Q_{c, p v}$ & Flow of water leaving from cells at portal vein \\
\hline$Q_{c, s}$ & Flow of water leaving from cells at sinusoids \\
\hline$Q_{f}$ & Flow of filtration from sinusoids to interstitium \\
\hline$Q_{h s}$ & Flow of Hipertonic solution \\
\hline$Q_{h v}$ & Flow of blood at the hepatic vein \\
\hline$Q_{p v}$ & Flow of portal vein \\
\hline$Q_{r}$ & Flow of reabsortion from interstitium to sinusoids \\
\hline$Q_{s, p h y s}$ & Flow of blood through sinusoids at physiological state \\
\hline$Q_{s}$ & Flow of blood through sinusoids \\
\hline$R_{s, p h y s}$ & Flow resistance of sinusoids at physiological state \\
\hline$S_{c, h a}$ & Cellular membrane surface at hepatic artery \\
\hline$S_{c, h p}$ & Cellular membrane surfac at hepatocellular plates \\
\hline$S_{c, p v}$ & Cellular membrane surfac at portal vein \\
\hline$S_{c, s}$ & Cellular membrane surfac at sinusoids \\
\hline$V_{c, h a}$ & Volume of RBC at hepatic artery \\
\hline$V_{c, h p}$ & Volume of hepatocytes at hepatocellular plate \\
\hline$V_{c, p v}$ & Volume of RBC at portal vein \\
\hline$V_{c, s}$ & Volume of RBC at sinusoids \\
\hline$V_{p, h a}$ & Volume of plasma at hepatic artery \\
\hline$V_{p, h p}$ & Volume of plasma at hepatocellular plate \\
\hline$V_{p, p v}$ & Volume of plasma at portal vein \\
\hline$V_{p, s}$ & Volume of plasma at sinusoids \\
\hline$V_{P}$ & Volume of the parenchyma \\
\hline$V_{s}$ & Volume of the sinusoids \\
\hline$\mu_{\text {phys }}$ & Blood viscosity at physiological state \\
\hline$\mu_{s}$ & Blood viscosity at sinusoids \\
\hline$\sigma_{e f f}$ & Effective electrical conductivity \\
\hline$\sigma_{L}$ & Electrical conductivity of liver \\
\hline$\sigma_{p, h p}$ & Electrical conductivity of plasma at hepatocellular plates (interstitial liquid) \\
\hline$\sigma_{p, s}$ & Electrical conductivity of sinusoidal plasma \\
\hline$\sigma_{s i}$ & Electrical conductivity of sinusoids and interstitium liquid \\
\hline$\sigma_{\text {solv }}$ & Conductivity of the solvent \\
\hline$\sigma_{p}$ & Electrical conductivity of plasma \\
\hline$\sigma_{s}$ & Electrical conductivity of sinusoidal blood \\
\hline
\end{tabular}




\section{REFERENCES}

1. Greenway CV, Stark RD. Hepatic vascular bed. Physiological reviews jan 1971; 51(1):23-65.

2. Greenway CV, Lautt WW. Hepatic circulation. Comprehensive Physiology. John Wiley \& Sons, Inc.: Hoboken, NJ, USA, 2011; 1519-64, doi:10.1002/cphy.cp060141.

3. Ananthakrishnan A, Gogineni V, Saeian K. Epidemiology of primary and secondary liver cancers. Seminars in interventional radiology 2006; 23(1):47-63, doi:10.1055/s-2006-939841.

4. Lencioni R, Crocetti L. Radiofrequency Ablation of Liver Cancer. Techniques in Vascular and Interventional Radiology 2007; 10(1):38-46, doi:10.1053/j.tvir.2007.08.006.

5. Kanas GP, Taylor A, Primrose JN, Langeberg WJ, Kelsh MA, Mowat FS, Alexander DD, Choti MA, Poston G. Survival after liver resection in metastatic colorectal cancer: Review and meta-analysis of prognostic factors. Clinical Epidemiology 2012; 4(1):283-301, doi:10.2147/CLEP.S34285.

6. Garcea G, Lloyd TD, Aylott C, Maddern G, Berry DP. The emergent role of focal liver ablation techniques in the treatment of primary and secondary liver tumours. European Journal of Cancer 2003; 39(15):2150-2164, doi: 10.1016/S0959-8049(03)00553-7.

7. Lau WY, Leung TWT, Yu SCH, Ho SKW. Percutaneous local ablative therapy for hepatocellular carcinoma: a review and look into the future. Annals of surgery 2003; 237(2):171-179, doi:10.1097/01.SLA.0000048443.71734. BF.

8. Castellví Q, Sánchez-Velázquez P, Berjano E, Burdío F, Ivorra A. Selective Electroporation of Liver Tumor Nodules by Means of Hypersaline Infusion: A Feasibility Study. 6th European Conference of the International Federation for Medical and Biological Engineering. 2015; 821-824, doi:10.1007/978-3-319-11128-5_204.

9. Weaver JC, Chizmadzhev Y. Theory of electroporation: A review. Bioelectrochemistry and Bioenergetics dec 1996; 41(2):135-160, doi:10.1016/S0302-4598(96)05062-3.

10. Davalos RV, Mir LM, Rubinsky B. Tissue Ablation with Irreversible Electroporation. Annals of Biomedical Engineering feb 2005; 33(2):223-231, doi:10.1007/s10439-005-8981-8.

11. Chunlan J, Davalos RV, Bischof JC. A Review of Basic to Clinical Studies of Irreversible Electroporation Therapy. Biomedical Engineering, IEEE Transactions on 2015; 62(1):4-20, doi:10.1109/TBME.2014.2367543.

12. Phillips Ma, Narayan R, Padath T, Rubinsky B. Irreversible electroporation on the small intestine. British journal of cancer 2012; 106(3):490-5, doi:10.1038/bjc.2011.582.

13. Scheffer HJ, Nielsen K, De Jong MC, Van Tilborg AAJM, Vieveen JM, Bouwman A, Meijer S, Van Kuijk C, Van Den Tol P, Meijerink MR. Irreversible electroporation for nonthermal tumor ablation in the clinical setting: A systematic review of safety and efficacy. Journal of Vascular and Interventional Radiology 2014; 25(7):997-1011, doi:10.1016/j.jvir.2014.01.028.

14. Kitao A, Zen Y, Matsui O, Gabata T, Nakanuma Y. Hepatocarcinogenesis: multistep changes of drainage vessels at CT during arterial portography and hepatic arteriography-radiologic-pathologic correlation. Radiology aug 2009; 252(2):605-14, doi:10.1148/radiol.2522081414.

15. Kapanen MK, Halavaara JT, Häkkinen AM. Open four-compartment model in the measurement of liver perfusion. Academic Radiology 2005; 12(8):1542-1550, doi:10.1016/j.acra.2005.07.001.

16. Kretowski M, Bezy-Wendling J, Coupe P. Simulation of biphasic CT findings in hepatic cellular carcinoma by a two-level physiological model. IEEE Transactions on Biomedical Engineering 2007; 54(3):538-542, doi: 10.1109/TBME.2006.888834.

17. Schwen LO, Schenk A, Kreutz C, Timmer J, Bartolomé Rodríguez MM, Kuepfer L, Preusser T. Representative Sinusoids for Hepatic Four-Scale Pharmacokinetics Simulations. Plos One 2015; 10(7):e0133 653, doi:10.1371/ 
journal.pone.0133653.

18. Lu J, Goldsmith MR, Grulke CM, Chang DT, Brooks RD, Leonard JA, Phillips MB, Hypes ED, Fair MJ, Tornero-Velez R, et al.. Developing a Physiologically-Based Pharmacokinetic Model Knowledgebase in Support of Provisional Model Construction. PLoS Computational Biology 2016; 12(2):1-22, doi:10.1371/journal.pcbi. 1004495.

19. Bickell WH, Bruttig SP, Millnamow GA, O’Benar J, Wade CE. Use of hypertonic saline/dextran versus lactated ringer's solution as a resuscitation fluid after uncontrolled aortic hemorrhage in anesthetized swine. Annals of Emergency Medicine 1992; 21(9):1077-1085, doi:10.1016/S0196-0644(05)80648-1.

20. Mazzoni MC, Borgström P, Arfors KE, Intaglietta M. Dynamic fluid redistribution in hyperosmotic resuscitation of hypovolemic hemorrhage. The American journal of physiology sep 1988; 255(3 Pt 2):H629-37.

21. Fosters K, Schwan H. Dielectric properties of tissues. Handbook of Biological Effects of Electromagnetic Fields, Polk C, Postow E (eds.). chap. 1, CRC press, 1996; 25-102.

22. Huang WH, Chui CK, Teoh SH, Chang SKY. A multiscale model for bioimpedance dispersion of liver tissue. IEEE Transactions on Biomedical Engineering 2012; 59(6):1593-1597, doi:10.1109/TBME.2012.2190511.

23. Trautman ED, Newbower RS. A practical analysis of the electrical conductivity of blood. IEEE Transactions on Biomedical Engineeringmedical engineering mar 1983; 30(3):141-54.

24. Solazzo Sa, Liu Z, Lobo SM, Ahmed M, Hines-Peralta AU, Lenkinski RE, Goldberg SN. Radiofrequency ablation: importance of background tissue electrical conductivity-an agar phantom and computer modeling study. Radiology 2005; 236:495-502, doi:10.1148/radiol.2362040965.

25. Grimnes S, Martinsen ØG, Martinsen O. Bioimpedance and Bioelectricity Basics. Academic Press: San Diego, 2000.

26. Peters MJ, Stinstra JG, Leveles I, He B. The Electrical Conductivity of Living Tissue: A Parameter in the Bioelectrical Inverse Problem. Modeling and Imaging of Bioelectrical Activity 2005; c(1967):281-319, doi: 10.1007/978-0-387-49963-5_9.

27. Archie G. The Electrical Resistivity Log as an Aid in Determining Some Reservoir Characteristics. Petroleum Technology 1942; (October):54-62, doi:10.2118/942054-G.

28. Glover PWJ. A generalized Archie's law for n phases. Geophysics 2010; 75(6):E247, doi:10.1190/1.3509781.

29. Wambaugh J, Shah I. Simulating Microdosimetry in a Virtual Hepatic Lobule. PLoS Computational Biology 2010; 6(4):e1000 756, doi:10.1371/journal.pcbi.1000756.

30. Schwen LO, Krauss M, Niederalt C, Gremse F, Kiessling F, Schenk A, Preusser T, Kuepfer L. Spatio-temporal simulation of first pass drug perfusion in the liver. PLoS computational biology mar 2014; 10(3):e1003 499, doi: 10.1371/journal.pcbi.1003499.

31. Greenway CV, Stark RD, Lautt WW. Capacitance Responses and Fluid Exchange in the Cat Liver during Stimulation of the Hepatic Nerves. Circulation Research 1969; 25(3):277-284, doi:10.1161/01.RES.25.3.277.

32. Garcia-Canadilla P, Rudenick Pa, Crispi F, Cruz-Lemini M, Palau G, Camara O, Gratacos E, Bijens BH. A Computational Model of the Fetal Circulation to Quantify Blood Redistribution in Intrauterine Growth Restriction. PLoS Computational Biology 2014; 10(6):9-11, doi:10.1371/journal.pcbi.1003667.

33. Eliakim M, Rosenberg SZ, Braun K. Effect of Hypertonic Saline on the Pulmonary and Systemic Pressures. Circulation Research may 1958; 6(3):357-362, doi:10.1161/01.RES.6.3.357.

34. Semler HJ, Shepherd JT, Swan HJ. Pressor effect of hypertonic saline on pulmonary circulation. Circulation research 1959; 7(November 1959):1011-1017, doi:10.1161/01.RES.7.6.1011.

35. Schmid-Schönbein H, Wells R, Goldstone J. Influence of Deformability of Human Red Cells upon Blood Viscosity. Circulation Research aug 1969; 25(2):131-143, doi:10.1161/01.RES.25.2.131. 
36. Keiding S, Johansen S, Winkler K, Tonnesen K, Tygstrup N. Michaelis-Menten kinetics of galactose elimination by the isolated perfused pig liver. The American journal of physiology 1976; 230(5):1302-1313.

37. Siggers JH, Leungchavaphongse K, Ho CH, Repetto R. Mathematical model of blood and interstitial flow and lymph production in the liver. Biomechanics and Modeling in Mechanobiology apr 2014; 13(2):363-378, doi: 10.1007/s10237-013-0516-x.

38. Pries AR, Neuhaus D, Gaehtgens P. Blood viscosity in tube flow: dependence on diameter and hematocrit. The American journal of physiology 1992; 263(6 Pt 2):H1770-H1778.

39. Blouin A, Bolender RP, Weibel ER. Distribution of organelles and membranes between hepatocytes and nonhepatocytes in the rat liver parenchyma. A stereological study. The Journal of cell biology feb 1977; 72(2):44155 .

40. Niehues SM, Unger JK, Malinowski M, Neymeyer J, Hamm B, Stockmann M. Liver volume measurement: reason of the difference between in vivo CT-volumetry and intraoperative ex vivo determination and how to cope it. European journal of medical research 2010; 15:345-350, doi:10.1186/2047-783X-15-8-345.

41. Muirhead E, Lackey RW, Hill JM, Bunde A. Transient hypotension following rapid intravenous injections of hypertonic solutions. Am J Physiol. 1947; 151(2):516-524.

42. Adrogué HJ, Madias NE. Hypernatremia. New England Journal of Medicine may 2000; 342(20):1493-1499, doi: 10.1056/NEJM200005183422006.

43. Ivorra A, Rubinsky B. In vivo electrical impedance measurements during and after electroporation of rat liver. Bioelectrochemistry (Amsterdam, Netherlands) may 2007; 70(2):287-95, doi:10.1016/j.bioelechem.2006.10.005.

44. Tyagi R, Donaldson K, Loftus CM, Jallo J. Hypertonic saline: A clinical review. Neurosurgical Review 2007; 30(4):277-289, doi:10.1007/s10143-007-0091-7.

45. Ajito T, Suzuki K, Iwabuchi S. Effect of intravenous infusion of a $7.2 \%$ hypertonic saline solution on serum electrolytes and osmotic pressure in healthy beagles. The Journal of veterinary medical science / the Japanese Society of Veterinary Science 1999; 61(6):637-41.

46. Tan TS, Tan KHS, Ng HP, Loh MW. The effects of hypertonic saline solution (7.5\%) on coagulation and fibrinolysis: An in vitro assessment using thromboelastography. Anaesthesia 2002; 57(7):644-648, doi:10.1046/j.1365-2044. 2002.02603.x.

47. Rothbarth J, Pijl MEJ, Vahrmeijer AL, Hartgrink HH, Tijl FGJ, Kuppen PJK, Tollenaar RAEM, Van De Velde CJH. Isolated hepatic perfusion with high-dose melphalan for the treatment of colorectal metastasis confined to the liver. British Journal of Surgery 2003; 90(11):1391-1397, doi:10.1002/bjs.4308.

48. Lin Yc, Chen Jh, Han Kw, Shen Wc. Ablation of liver tumor by injection of hypertonic saline. AJR. American journal of roentgenology jan 2005; 184(1):212-9, doi:10.2214/ajr.184.1.01840212.

49. Romano L, Grazioli L, Bonomo L, Xu JR, Chen KM, Dore R, Vanzualli A, Catalano C. Enhancement and safety of iomeprol-400 and iodixanol-320 in patients undergoing abdominal multidetector CTL Romano. British Journal of Radiology 2009; 82(975):204-211, doi:10.1259/bjr/93627766.

50. Bucher AM, De Cecco CN, Schoepf UJ, Meinel FG, Krazinski AW, Spearman JV, McQuiston AD, Wang R, Bucher $\mathrm{J}$, Vogl TJ, et al.. Is contrast medium osmolality a causal factor for contrast-induced nephropathy? BioMed Research International 2014; 2014, doi:10.1155/2014/931413.

51. Zhuang J, Kolb JF. Time domain dielectric spectroscopy of nanosecond pulsed electric field induced changes in dielectric properties of pig whole blood. Bioelectrochemistry (Amsterdam, Netherlands) 2015; 103:28-33, doi: 10.1016/j.bioelechem.2014.08.009.

52. Geddes LA, Baker LE. The specific resistance of biological materialA compendium of data for the biomedical engineer and physiologist. Medical \& Biological Engineering may 1967; 5(3):271-293, doi:10.1007/BF02474537. 
53. Laufer S, Ivorra A, Reuter VE, Rubinsky B, Solomon SB. Electrical impedance characterization of normal and cancerous human hepatic tissue. Physiological measurement jul 2010; 31(7):995-1009, doi:10.1088/0967-3334/ 31/7/009.

54. Haemmerich D, Staelin ST, Tsai JZ, Tungjitkusolmun S, Mahvi DM, Webster JG. In vivo electrical conductivity of hepatic tumours. Physiological measurement may 2003; 24(2):251-60, doi:10.1088/0967-3334/24/2/302.

55. Lautt WW, Greenway CV. Hepatic venous compliance and role of liver as a blood reservoir. The American journal of physiology 1976; 231(2):292-295.

56. Debbaut C, Monbaliu D, Casteleyn C, Cornillie P, Van Loo D, Masschaele B, Pirenne J, Simoens P, Van Hoorebeke L, Segers P. From vascular corrosion cast to electrical analog model for the study of human liver hemodynamics and perfusion. IEEE Transactions on Biomedical Engineering 2011; 58(1):25-35, doi:10.1109/TBME.2010.2065229. 